\title{
Culture at the Bottom of Startups: Reflections on Social Expectations
}

\author{
Cristian Mendoza ${ }^{1}$, Eric Salobir O. P. ${ }^{2}$ \\ ${ }^{1}$ Pontificia Università della Santa Croce in Rome, Italy \\ ${ }^{2}$ General Promoter of the Order of Preachers for Social Communications, France \\ Correspondence: Cristian Mendoza, Pontificia Università della Santa Croce in Rome, Italy.
}

Received: November 7, 2016

doi:10.11114/smc.v5i1.2202

\author{
Accepted: January 3, $2017 \quad$ Online Published: February 6, 2016 \\ URL: http://dx.doi.org/10.11114/smc.v5i1.2202
}

\begin{abstract}
This article aims to define the culture at the bottom of the development of "startup" initiatives (or the startup movement). These are initiatives for improving an organization in three different ways: asking creative groups to collaborate with larger organizations for solving specific problems; inviting creative groups (hubs) into larger institutions for searching new ideas; and setting up collective spaces for the sake of public relations. I aim to define if the promotion of startup initiatives could be adequate for faith-based institutions such as the Catholic Church. Startup hubs are growing faster in our world, due to the common perception of social discomfort in regard to the political, economic or social systems. Not every creative initiative is a startup, as these initiatives aim to improve the system from within, thanks to mutual collaboration. Therefore they require common ground and respect for the principles of the larger body. Most startup hubs refer today to technological development, but some of them aim to enhance collective expectations. Our thesis is that some startup hubs could also be set up for changing personal behaviors. Startup hubs with the scope of changing personal lifestyles could also modify cultural interactions, becoming very attractive for faith-based institutions and also for the Catholic Church.
\end{abstract}

Keywords: startup, Catholic Church, social expectations, cultural challenges, hope

\section{Defining Startup Initiatives}

Startup hubs were born in the last decades of past century, when large multinationals decided to address the fact that a good amount of small issues, regarding for instance, customer service or marketing improvements, could not be faced by the leadership of the company. With the large companies mostly focusing on the core business of the organization, they were leaving behind some minor although relevant issues for the commercial institution as a whole. Paradoxically, the success of startup initiatives is defined on their capacity for proposing capital investments and personnel developments for reinforcing "the non-pecuniary benefits of innovation-driven entrepreneurship" (WEF 2014, 15). This means that their appraisal is done on their ability for proposing solutions to a system, from outside of it.

In Germany the number of startup initiatives uniquely passed from 36,700 to 42,000 in four years-2008-2012-(WEF 2014, 19). For instance, Lufthansa, one of the largest airplane transportation companies, created significant startup initiatives calling for creative groups and smaller enterprises, asking them to design solutions for customer care (hub.lh.com). The result was that a dynamic group of young creative entrepreneurs and small creative institutions provided the German multinational with real solutions. Each small company and group of professionals who participated in the initiative created a startup project for Lufthansa. One hub created a new banner for the web site, a second one created a new app for solving a problem, and a third one designed a paper brochure to be distributed in the planes. Lastly, another startup hub gave Lufthansa a course for suggesting ideas to employees dealing directly with key customers.

Inviting niche companies and experts to work within larger companies for a specific period of time constitutes a first mode of startup hubs. Large multinational enterprises are currently using these hubs to determine real problems which are usually secondary to the core business of the organization. But for a large company, this means making an investment which could return around ten times its value, considering the arc of solutions given to the leadership of the larger institution and to the different stakeholders: customers, clients, investors, etc. The use of startup hubs for an institution to identify key problems appears to be very successful today.

There is a second kind of strategy for putting startup hubs in place. They do not result from one or more minor problems 
that a large institution or its leadership has been able to identify. They are in place rather when larger institutions call for smaller companies or creative groups, not aiming to solve specific issues but looking for new ideas and products. This seems to be the case for BMW, an enterprise opening up its laboratories to some creative young professionals, inviting them to join the company for few months (usually around three) in order to apply their professional creativity and fresh ideas to BMW products and technology. At the end of the stipulated time, the larger company can renew the contract or decline it.

This second kind of startup helps the leadership of the company to generate new and better products. However, the impact of these startup is harder to measure, as they do not aim to resolve a problem. The necessary investment to put them in place is thus seen more as an expensive product development, or even as gambling. These kinds of startup hubs are not as efficient as those focused on defined issues.

Finally, there is a third typology of startup initiatives that are in place neither on the need to solve a problem nor to find out new ideas. This group of startup initiatives is a call that large enterprises address to creative groups only for the purpose of public relations. Creative groups and smaller companies can visit the institution which is approaching new publics to the enterprise, but without real involvement or participation. This mode of startup hubs is however important and significant, as it allows enterprises to open themselves up, being therefore exposed to new perspectives. Putting in place these kinds of public relations hubs is for prestige, as the company acquires the status of being in startup mode, which is usually understood as openness and transparency, highly appreciated by the public sphere (Hood 2006, 3).

The future development of technology and of business in general seem to be driven by these kind of initiatives, providing solutions, improving the system or making the institution more attractive, working for the benefit of a larger social organization while acting from outside of it. In order to define startup initiatives as an answer for our collective expectations, we could consider them as an answer not only to our wants but also to our needs. Startup hubs should therefore not only aim to improve our social organization, but can also be in place for proposing new and creative solutions for people -for whatever reason- acting outside of our current political, economic and social systems. In the last sense, startup hubs can be a positive challenge for organizational models based on competitiveness or marketing.

It is our understanding that both kinds of hubs (aiming for social improvement and for creative human development) are already in place today, at least to some degree. But we also observe that our social order still needs more initiatives, aiming to develop human dignity independently of the improvement of the systems conforming the new social order, even if "their substantive significance is probably not great because group factors are likely to override individual ones" (Ragin and Becker 1992, 35). Putting in place a third mode of startup hubs (aiming for cultural development) could tell us more about the reason of startup developments, as the third mode could go beyond the social, political and economic actors' desires. Technological development is attractive and it can be always more attractive by giving space to personal creativity through startup hubs. These could become even more significant for our society, by the measure in which they could give birth to new social, political and even economic institutions, tailored according to human needs.

\section{Understanding the Startup's Relevance}

In the recent years, several startup initiatives have been flourishing among public and private actors of society. Their success in bringing collaboration and new ideas within institutions is such that the faithful are asking faith-based communities to develop them within churches and religious groups. In the specific case of the Catholic Church, its leadership is putting attention to the startup hubs not on the search of new ideas but rather on the fact that these initiatives respond to and at the same time enhance our collective expectations.

Habermas observed that the whole dynamic of society is built upon collective expectations (Habermas 1990, 138). For him, there are two principal possibilities for the studies of social sciences: One is positivism tending to analyze only what objectively appears to us as human behavior. The other one is an action theory, implying not only what appears to be human behavior but the self-understanding of the subject who behaves in a specific way. Habermas' action theory challenges us to get not only an 'explanation' of society but also an 'understanding' of symbols that cannot be rightly apprehended through observation, rather requiring a subjective explanation of them.

That explanation should be given by the language of ordinary life, which every individual learns mostly in the interaction of social expectations, in the understanding of what others expect from him or her. For instance, complaining when secular citizens do not go to church anymore is useless, if we do not understand that the language used in faith-based communities is addressed to those aiming to think together about "meaning of life" questions, i.e., questions regarding death, pain, afterlife, etc. But if Westerners do not think about these questions, they will not try to ask others about their own reflections, and so might not go to church anymore (Pannenberg 1986, 15).

The real problem is not what is observable -people not going to churches- but rather that people do not think anymore about those questions. Understanding some of the current collective social expectations could be key for disclosing part 
of our culture, avoiding positivism and learning how to communicate 'who we are' in ordinary language. We will describe some manifestations of startup trending in current social development, aiming to understand if and how we could apply to faith-based institutions.

People living in western societies, such as most Europeans and Americans, experience a continually-faster technological development. Some politicians and members of academia are aware that wide and constant access to information is becoming a social challenge to the point of defining western society as 'infoxicated' (Herrera 2016). Scholars focusing on technology give us a better idea of what is happening, defining its consequences and calling our attention with regards to potential threats for future generations, which they consider growing up distracted (Carr 2010, Howard 2015). There are fewer attempts though to explain why technology is distracting us or, to say it in a positive way, why it attracts us so much.

We will argue that technology is attractive to human beings, as it becomes instrument and platform for participating in our current social order. But in this definition we cannot go forward without recognizing that it is too general as a thesis to be immediately defined. The social order that we are referring to is the western social order requiring from every participant a certain degree of technological mastery. Following Taylor we understand that this social order does not have geographical, educational or economic boundaries, as it has become global and cross-cultural.

Four strong benchmarks of the new order are: liberty: the move is meant to liberate; power: it is meant to empower; mutual benefit: this is the basic point of society; and reason: whether freedom, power, mutual benefit has been achieved, or how to achieve them, is meant to be arbitrable by rational discussion (Taylor 2007, 578).

We could understand that technology makes us free, as thanks to it we are able to tell others lots of things about our lives, and we get to know almost anything about other people whenever we want. Technology empowers us for hiding or showing our self-possessed world on-line, making public not what we are but what we desire to be. It becomes more and more a transactional platform where we do not risk others' knowledge of us, but only of our information sharing. This appears as an inevitable situation which it is not necessarily negative, as at the bottom of the exercise of our freedom, power and mutual benefit, we can always find ourselves aiming to build up our personal skills and so also our family and society. Startup initiatives referring to technological development, once in hands of important enterprises, are now flourishing in smaller hubs, becoming a sign of the interaction among faith-based institutions, the free market economy and the leaders of digital culture. So their collaboration is translated under quality exigencies where non-profit is not equal anymore to non-professional, and where every public institution is expected to invest some talents and resources in startup mode.

Two different reasons foster therefore the use of information and communication technologies (ICTs) today. One is the fact that currently many people get to know something about us through ICTs, and we naturally want to be in relation with others. The other is that it is easier to modify others' conceptions of us in the virtual world than in reality, although we could rightly observe that the virtual world is a real one. We tend to qualify ICT instruments on their ability to make us attractive-or at least acceptable-for others, opening our 'public profile' to others, and on their effectiveness in creating personal relations, helping us to reach 'public attraction'. It seems reasonable to think that if people devote so much time to the use of ICTs, it's because in them they can express their self-conception and enhance through them their public attraction.

The development of ICTs also has economic drivers, as the flourishing industries of California's Silicon Valley show us. California's billionaires own a combined $\$ 560.1$ billion in wealth, which is more than the combined GDP of 49 countries. And the constant trend of technological development is finding new fields as "there are some estimates, however speculative, that the so-called 'smart cities' technology market may be worth anywhere from $\$ 100$ billion to $\$ 1$ trillion over the next decade" (Rabari 2013,2). Some scholars express grief over the great dedication of talents and intellectual efforts for developing fields that are neither humanistic nor scientific but just efficient to operate transactions in a system (Llano 2016, 32).

Several of these efforts are moving now towards the form of business initiatives called startup, growing at high-speed rates in the new social order as "concrete, contextualized knowledge is therefore more valuable than a vain search for predictive theories" (Basic 2015, 7). The talent, time and public attraction that startup hubs are getting allows us to count them today among the most important manifestations of social expectations, which will be leading future changes in society.

\section{Culture at the Bottom of Startups}

Being aware of the importance and development of startup hubs, we can now try to inquire about the motivation their creators have for promoting them. The dynamic of modern society is built upon collective expectations configuring 
standards of behavior for each one of its members (Scruton 2009, 183). One of the most valued behaviors is 'creativity,' now acquiring more and more cross-cultural importance, having as one of its manifestations the startup hubs' development. They are the expression of the current need of creative people, ideas and institutions in political structures, civil associations and enterprises. Collective expectations regarding several of our interactions in politics, economy and social movements influence our personal behavior, and also the configuring of our public structures. The complex interaction of personal behaviors in social structures, both depending on collective expectations, is what we understand as "culture."

Every society can be shaped by one or more cultures, as collective expectations are not the same-sometimes unjustly-when referring to different ages, educational levels, religions or sex. The use of startup initiatives finds legitimacy on the understanding of the culture laying behind them. For instance, the political square should take into consideration the collective expectations of the citizens who have entrusted political rulers with power. But this would not be the case of the leadership of a commercial institution, usually considering not only its employees' expectations, but more those of its stakeholders'.

Collective expectations configuring a specific culture in society could be even less demanding for a non-profit institution. In fact, many times these institutions aim to fill a gap in social services, left behind by political or economic actors in society. And finally, for the faithful of a religious body, the collective expectations do not configure their most important standards of behavior. These institutions do not change according to digital trends, although the last category could reflect real problems of ordinary life. A utilitarian vision of the institution, its clergy or sacraments, would not reflect the identity of a religious body. In faith-based institutions we observe a specific behavior model inspiring action: The life of the divine (a Prophet, Jesus Christ, Mahomet, Buddha, etc.) roots the personal behavior, so that collective standards can flourish in obvious contrast to the general environment, giving place to new collective expectations, able to modify many cultural fields like politics, economy or education. Collaboration within faith-based institutions, through startup initiatives, will grow when the institutions are put in place not for solving personal needs but for aiming to reach communion for all the faithful in the long term.

For understanding the intention of startup initiatives, we would need to define if they are driven towards technological creativity, or if they aim to modify collective expectations of one or more cultures, or if they could impact the personal behavior of several members of society. At the instrumental level, startup hubs become a significant engine for progress and are positive for society, when they are sustainable from an ecological and economic perspective in respect to human dignity. Technology is truly very important, but it does not seem to be enough for creating human culture. So startup hubs can flourish, not focused on techniques but on our want for changing collective expectations regarding the economy, some civil society initiatives, democratic institutions and information sharing.

In a sense, bottom-up political parties and think-tank organizations could fit into the category of startup mode, except that most of them do not collaborate or participate with larger societies in their common cultural field. The theoretical understanding of the new social order is inclusive and its leaders ensure that the system is built for everybody, not only for the privileged by blood, race or beliefs. It gives place to institutions like the United Nations, the European Union and the International Monetary Fund, aiming to improve free market economy, social foundations and technological development. These institutions have common grounds, and ideally the development of each one of them would lead to strengthen the others. In theory the attractiveness of technology and the personal creativity involved in developing startup hubs would also lead to improvement of our social order's institutions.

There are some tensions though, not allowing us to immediately accept the aforementioned statement. More and more people observe that current economic, political and social relations are no longer at the center of our technological development. What seem to occupy the focus of social interaction is production, economic profit and power. Thinkers and religious believers challenge therefore the cultural habits of our western society. What the challengers have in common is that they do not usually belong to the system they are contesting. Startup initiatives develop when a need for creativity is noticed. They find space when we face what Taylor called the malaise of modernity (Taylor 1991).

Nowadays the most debated pillar of the new order seems to be the free market economy, where the social order is challenged by some scholars asking themselves if it is fair to live in an economic system where the poorest $40 \%$ of the world population owns practically nothing, especially if contrasting their income with the national debt of their countries (Atkinson 2015, 166). Likewise international organizations do not find normal that "while nearly a third of the planet lives on less than $\$ 2$ a day, the richest 85 people in the world own more wealth than the bottom half of the entire global population" (WEF 2015, 5). Some religious leaders observe that we have created a throwaway culture, rejecting raw materials, used instruments and people all in the same way (Francis 2013, 53).

The political environment is not safe from questioning either as sometimes it appears too closely linked to economic dynamics. There seems to be a sort of disenchantment with the world, especially when realizing how easily we can be 
excluded from society. Economic development has not created inclusive societies but rather exclusive worlds (WEF 2015 , 2). There are groups of people in our own homelands that are not allowed to receive the same education and opportunities as our family members. And the western world no longer has the same geographical bounds, which means that social differences grow always clearer and closer to us, thanks to technological developments. Politicians answer that it is not the first time we are invited to think about our cultural behavior, as two hundred years ago we faced racism and slavery, 150 years ago we strived for democracy and freedom, and only 50 years ago we were claiming for education and welfare. The truth is that politics should be part of the equation to balance the power of the economy (Francis 2015, 164), but their expected role seems to rarely be assumed.

Moreover, ICTs sometimes aim to gain public relevance. For instance, when Facebook proposes its users to inform their relatives about their being safe after an accident or attack, in some regions it could mean almost to assume the role of the State. The web is the new platform where we learn about the world, but when inquiring in it, we use our own language and look for things that are part of our self-acquired interests. The web, as open it might seem, naturally becomes an instrument which filters reality, operating a media-doubling of the world, making our world's conception always more specific and leading us to focus on our own cultural backgrounds. "The internet is the medium "par excellence' for people to self-select interaction with like-minded people, which can lead to fragmentation and polarization" (Carty 2015, 25). In the case of faith-based institutions, startup offering 'attention' and 'services' not available outside of the institutional religious body could not necessary lead to communion, but it might lead to dispersion, making of the spiritual mission a private affair.

Even when trying to reach different cultures and to learn more about others, we should be aware that ICTs present not reality in itself, but only a public or publicized reality. We live in a world full of closed environments where those looking forward for knowing our societies and lifestyles learn neither the real difficulties we face nor the efforts we make. The work we do to organize our world seems to be unknown for too many. Foreigners learn about us only what is public and advertised, not the reality behind our publications. One of the consequences of the way in which we make our world public is the hiding of our weaknesses and efforts. And when external observers learn our public presentation regarding certain regions of the world, we can easily generate jealousy or even envy and discomfort.

The attractiveness of what appears as an easy life becomes a threat for those living excluded but connected with always higher technological societies. Terrorism, violence and other injustices could be the fruit of our being familiar with an apparent global communication in western societies, operated by the advertisement of the virtual world, which is-sometimes unfortunately-extremely real.

\section{Society as a Body}

Startup initiatives flourish when a need for creativity is noticed. They find public space when we acknowledge social unease. Social expectations for western culture are the protection and respect of those need and for the powerful likewise an exigency and challenging on their responsibility. Several social criticisms are perceived today with regards to the free market economy. Post-capitalism is neither referred to as socialism nor as controlled economic systems. It aims to keep the positive development reached thanks to the free market economy, but including at the same time those who were left behind. The challenge is to be aware that " 2.5 billion people don't have access to adequate sanitation; more than 1.6 billion people lack access to electricity and modern forms of energy; about $12 \%$ of global population suffer from chronic hunger" (WEF 2015, 5).

Post-capitalism developments appear in the Bitcoin movement, where international monetary institutions or financial systems would not be needed for transactions. The new economic order aims to be grounded on participants' common trust. We observe therefore a constant development of secondary economies for renting cars, having accommodation in foreign cities or getting cab transportation. The economic system is challenged. We cannot keep living on profit-centered free-market transactions of pleasant pleasures, so "we can no longer trust in the unseen forces and the invisible hand of the market" (Francis 2013, 204). And "economic activity cannot solve all social problems through the simple application of commercial logic" (Benedict XVI 2009, 36).

Our current social and economic system has 'malaise' symptoms (WEF 2015, 12). This malaise is more than an expression, as it could recall that western society understands itself as a living body, growing on the collaboration and interchange of different organisms. The State, the churches, enterprises, associations and other groups configure the entire environment where every member may find freedom and development for his capacities, contributing with her or his talent to others' development as well. The body model for society allows westerners to stress that every single part is important, and if truly each organism has its function, it is not possible to exclude or ignore some members of society in benefit of others. Resources and talents are devoted to improve institutions, because these provide benefits for the development actors in every system. Startups are attractive for religious faithful in forms of social networks to pray, offering 'religious' housing or experiences, mobile apps for coordinating relief services or instruments for finding a 
confessor or for giving alms. But these initiatives move faster than the institutional body, so the resources creating them might respond to their creators rather than to the long-term tradition of the religious body, moving outside of economic and political motivations.

Faith-based institutions actually understand that challenging the economic model is a condition for living democracy in service for integral human development (Francis 2015, 109). Their challenge is not against reasonable economic development. It is a moral consideration falling beyond every economic equation: Our human choices take place when we are well aware of our being humans, when others understand us as persons with equal dignity. So, they stress that what creates economic poverty is moral poverty and that the latter is constraining democratic developments. Some scholars appreciate this line of thinking, stressing that, "in less than half a century China alone has managed to transform the livelihoods of some three hundred million of their people, shifting them from abject poverty to economic standards that rival the West" (Moyo 2012, 19). We are also aware that overcoming economic poverty requires overcoming moral poverty, as the lack of education and formation could produce corruption and injustice. Solving economic poverty without putting attention to moral poverty could be a risk of time and resources. And startup hubs could be created for this.

Another of the malaise's symptoms is found in the weakness of our current political systems in their task of leveraging human dignity. Some thinkers claim is not due to the State, whose function seems to be keeping a sort of common good that ancient philosophers defined as public justice and health (Jaeger 1957, 656). Leveraging human dignity is not the focus of a State organized for reaching economic and technological goals (United Nations 2016, goal 13b), but it can be done by institutions created without teleological finalities, like faith-based organizations, aiming to preserve traditions and religious beliefs. Making democracy true in the midst of poverty and lack of education requires moral attention, asking us to consider not if the free market is useful, but if the free market is free; to know if current a vailability of information makes us free from political strategies and other social categories; to strive for what is really human and relational instead of only getting material satisfaction.

Creating social exclusion makes us feel an economic malaise (WEF 2015, 4); when we observe powerful social leaders hiding information we suffer; it discomforts us when we notice that political rulers generate injustice and promote soldier boys. It is on that unease that startup initiatives for changing collective expectations are born, asking for the regulation of new financial instruments, for home-based working opportunities, for microcredit banks, or for shortcuts in order to resolve health bureaucracy. Startup hubs appearing merely as initiatives for technological development are not a full answer for social needs. Some startup initiatives born in western society aim therefore to bridge a gap in full respect of what society is: an interaction of groups and people analogous to a body.

Habermas, in his dialogue with Parsons, observed that society does not aim for specific goals but rather strives for keeping the status quo of social life, allowing every member to develop to the point of "as good as it gets" (Habermas 1990, 161). After the experiences of past century, believing in social goals and plans has withered away, so Luhmann years ago already realized that "model calculation and reality now converge, it seems, in the prediction of unpredictability" (Luhmann 1997, 360). Startup initiatives in their modes and technology become 'disruptive', able to create 'perturbations' in established systems, so they are flourishing in the measure in which they leverage the minority condition of those putting them into existence. This could be one of the reasons why the State, many other institutions and most religious bodies are not promoting startup hubs in their organizations.

We need to face the fact that public institutions are in place to answer to collective expectations but at the same time they depend on them to subsist. And so not every initiative coming from outside a system becomes a startup. Some scholars challenge democracy, thinking that we should not leave social development in the hands of private investors, but they do not constitute startups. When the government participates in social development, it not only gives back national debt to citizens, it also leaves them social infrastructures like electricity, roads and public transportation. According to some scholars these kind of decisions are not taken in a democratic way, and if the government decides to invest in specific companies, it should take out from them revenue which would be an easier way to obtain funding, apart from taxes. In their opinion, the government "should welcome (rather than shy away from) the risky territory of blue sky research, facilitating networking between business and academia, and engaging in pre-commercial procurement to a far greater extent" (Mazzucato 2011).

Including the government in the economic equation would change society but would not represent a change from inside of it. Startup hubs create new societies inside of larger institutions, giving place to new currencies and social aid. These initiatives stress that social inclusion is not only built upon knowledge and technology, but also on education, availability of time and human opportunities. We live on the common understanding that accessibility is inclusion, but the need of startup hubs shows that connectivity does not mean social inclusion, human achievement is not the same than economic development, and free market is not immediately democracy. So "politics must not be subject to the economy, nor should 
the economy be subject to the dictates of an efficiency-driven paradigm of technocracy" (Francis 2015).

There are many positive symptoms as for instance technological development has given us a unique opportunity, the one of creating a global community. Although knowing all about a specific reality does not mean that we will change it, we really know what is happening in the whole world and we are able to understand it better. Our technological improvements lead us to the point of having an easier and better life. It has been very positive in terms of education, health and global development. It is only that the observation of significant social differences leads us to search for new solutions. What would happen when the internet will be a new economy with its own currency, language and laws? Would we then have a political structure based on two different economic systems? Even if that happens, the cultural background behind it would still be the same. So, the question regards not the tools but the culture driving the use of economic, political and social instruments: individualism or service; human dignity or profit. Those goals are always mixed in society, but which degree would be better, which one is right?

Democratic institutions take into consideration the common good and not only specific goods or goods just for a few ones. There seems to be little or no space for startup initiatives aiming not only to create better instruments but actually looking for new social expectations and to deeply change our cultural interactions. There is more than ever a need to know that "economics without politics cannot be justified, since this would make it impossible to favor other ways of handling the various aspects of the present crisis" (Francis 2015, 196). Faith-based institutions, as is the case of religious bodies, do not base their cultural interactions on public opinion. Those belonging to these kind of social organisms do not respond to collective expectations but rather behave imitating the specific life of Someone they understand as a life model, a divine one. In this sense, faith-based organizations challenge collective expectations in their modeling of personal behavior.

\section{Challenging Collective Expectations}

Initiatives challenging the current social order cannot be isolated from the values giving origin to that order. Democracy and its institutions as we know them today were born from the understanding that all men are equal. Equality was the base for a common understanding giving place to public demands of transparency and accountability. It is a gradual trend, as at the beginning women were less equal and slaves were not as equal as free citizens. At the base of democracy we can find personal dignity; without personal dignity, no democratic movement could arise. A similar trend can be observed in free market economy development. Its system was based upon the understanding that human beings cannot foresee everything, and so a single individual could never be able to govern such complexity. The system was needed to protect the individual, and not be driven on economic goals.

Many of the institutions of society which are indispensable conditions for the successful pursuit of our conscious aims are in fact the result of customs, habits or practices which have been neither invented nor are observed with any such purpose in view (Hayek 1976, 11).

The World Economic Forum community observes that social systems are attractive for their enhancing of personal creativity. Social interaction is built upon personal responsibility, united to a special kind of liberty. Without freedom there is not responsibility, and society should recognize "the fundamental and positive role of business, the market, private property and the resulting responsibility for the means of production, as well as free human creativity in the economic sector" (John Paul II 1991, 42). In the political history of Nations we have always balanced the values of modern times. We have created societies stressing equality and forgetting liberty, and others created societies stressing liberty but ignoring equality. Curiously, no one has dared to stress fraternity, as it is not profitable for any group in the economic equation.

We ask ourselves now which would be the culture laying behind technological developments today. If the technological trend answers our way of being humans, it should also reflect some human dimension. Connectivity today seems to be linked especially to human relational capacity. For every person, being in relation with others, means to fulfill our way of being humans. It is only in human interaction that we are fully aware of who we are and why we are on earth. It seems that the growing of our world's awareness means for us the natural expansion of our self-capacity of being in communication. We are more and better in the measure in which we communicate with new worlds and with more people.

We observe that faith-based initiatives foster a relational culture and a good number of cultural examinations can be carried forward thanks to the development of ICTs. For instance, the creation of a hackathon (digital experts meeting) in Paris by the research center OPTIC, aiming to foster solidarity, spirituality and cultural promotion startups is an expression of how collaboration is translated in cultural interactions. The witness of someone whom we do not know and may never meet face to face, can make a difference in our life today thanks to developments of ICTs. But the change is always made from one person to another, from one individual to another. "A person's work is naturally interrelated with the work of others. More than ever, work is work with others and work for others: it is a matter of 
doing something for someone else" (John Paul II 1991).

Understanding the importance of being in relation with others through ICTs helps us to establish human links and to learn that "young people often fail to find responses to their concerns, needs, problems and hurts in the usual structures" (Francis 2013). The relational culture created by faith-based initiatives carries today several names, appearing under modalities that we call sustainability, intergenerational justice or charity and even sometimes, universalism. Current cultural examinations could be operated through startup hubs and similar social movements bearing important consequences for the public square. Because,

5.1) Social institutions with unreachable dimensions for us as humans are starting to disappear. The greatness of the European Union's operation has recently been challenged by the exit of one of the Nation members. The amount of information required to ensure global peace is no longer in the hands of few people. We live an atomization of the world when new generations aim to understand their social order within human sizes and meanings. Once again, small is beautiful (Schumacher 1973).

5.2) Dissatisfaction is the negative name that a part of current technological, economic and social improvement is having. On the contrary, personal improvement is usually what human beings look forward to in society. Dissatisfaction can only be a bad reality when it is disconnected from the consideration of real human dignity.

5.3) Closed societies build up spaces for interaction and sometimes they even do it physically, for instance in some Countries there are entire areas designed only for foreigners as structures of common understanding. While there is high competition in material interchanges, human values are enclosed in ghettos needing to be opened in order to spread out their contents. Spreading out human value can make the difference for every member of society. Startup hubs know that only performative enterprises, i.e., those able to change clients, investors and workers' lives, will last in the long run (Laudicina 2012).

5.4) Although some authors affirm that making good means making well-as you may earn more money if you do the right things-there is something in that affirmation sounding instrumental with regards to the economy. Western societies do well but they have lost focus on working well, and that is why is so hard to include in their economic equation the good that is united not to economic profit but to human work.

5.5) There is a lot of voluntary unemployment. "Nearly twenty years ago, Amartya Sen ended an article with the statement, 'It is amazing that so much unemployment is so easily tolerated in contemporary Europe" (Ackinton 2015). And we know that the western society is being acquired by other worlds, which would not only be an economic purchase, but a cultural one.

"In the case of the UK, the 2012 survey of the beneficial ownership of UK ordinary shares showed that over half were owned by "rest of the world" investors (up from under one-third in 1998 - a striking indicator of the way the world is changing)" (Ackinton 2015).

Cultural shifts can be observed in the fact that today there is a real difference among property and control, and between wealth and capital. Pension funds owners have not possibility to determine where their money is going to be invested, so we live as Luhmann observed facing "the control of intransparency" (Luhmann 1997). Owning a house is not anymore expression of being wealthy, as due to demographic decline and mortgage systems we can dispose of capital still being poor. Both systems, real estate and financial investments are subject of economic debates and likewise, political achievements look at economic development regarding property and capital, rather than control and wealth.

But the use of human beings as parts of a system requires cultural understanding. Who is keeping control of economic and financial systems and to what purpose? Social, political and economic positions can be held according to intellectuals' collective expectations. Political philosophers reflecting in the midst of heavy State intervention and control could be attracted by economic systems aiming for de-regulation and operational freedom (Rodríguez-Luño 2016). On the contrary, thinkers reflecting in high free economic systems may stress the importance of filling the social gap they observe, so calling for social collaboration.

What remains at the end of our cultural examinations? Can we really expect an easier future for the next generations and a better personal development based on technology, democracy and economic developments? That would be hard to tell. Not by any chance some thinkers affirmed that western societies are less and less kindled, like if they would start to lose hope. "Modern societies are built upon science. They owe it their wealth, their power, and the certitude that tomorrow far greater wealth and power still will be ours if we so wish" (Monod 1970, 170). The crisis of western society is a crisis of hope. The deepest challenge regards our personal behavior.

\section{Conclusions}

Habermas observed that our hopes and fears in society are driven by urgent issues worrying us, but their solution is not in 
urgent actions. According to the philosopher, hope and fear are only solved in a long term understanding of our being with others, sharing in society (Habermas 1990). The exercise of measuring urgency against memory is what we are trying to define as hope. It guarantees the human dimension of work in society and also of the development of current startup. When hope is real, it allows us to escape from false appreciations, from easy earnings and from injustices toward others. On the contrary, when we lose hope, our life gets reduced to immediate satisfactions. We could perhaps imagine that losing hope would be like experiencing a deep desolation, or an interior anguish that is wordless. It is not usually the case. Tired and depressed people struggle a lot, according to their real capacities, and hope is living in them (O'Callaghan 2011, 4). Losing hope could be something that happens unobserved, almost without pain. It is neither anguish nor lack of consolation. It is all about our self-conception, we leave behind responsibilities that in the long term will lead us to lose hope. It is fruit of a lack of consideration of ourselves and of our reality.

It is mostly on the understanding and belief that we can-and should-behave in a way that does not fit with collective expectations that we can change our cultural interactions. It requires the manifestation of others' personal success when facing the worst human troubles, making us aware that there is a way for overcoming social malaise. And even if pain and death will always accompany us, we also know that the only pain we cannot overcome is senseless pain (Romera 2016, 17).

When faith-based institutions such as the Catholic Church aim to create startups for cultural and personal changes, they should foster dissatisfaction. Social unease is one of the most important engines for social change and, for faithful of religious organizations, the only way to create change is to make evident our social malaise. Only then can we stress that this world should be better, moving people into action. It was perhaps on this principle, thinking about the future of society, that Aristotle defined work in relation to expectation or hope, as both human expectations and work aim to reach the same goal: a good not present, hard to obtain, yet possible to get (Flannery 2013, 229).

Modernity brought a great confidence in the human capacity to understand and to change the world. The hope that was at the base of our actions changed into hopes on science and technique, so that the ancient hope was now called progress. Christian hope operates with commitment to changing our common world for the sake of making another world better, with the condition of knowing that material realities will not last forever. Social imagination has united back again in our days a certain conception of work and human expectations, thanks to massive technological development. Hope has likewise recovered a sort of Aristotelian character, becoming intrinsically linked to work. Fromm thought that hope was becoming a right only for a few chosen. Those who have the real capacity to make a difference own hope as a right, the others can only aspire to a passive hope (Fromm 1968, 23). For him hope is only significant for specific groups of people. Those who live on hope can make things change, the rest live on other's power for changing society. Fromm spoke about active and passive hope in this sense. The hope of those who can improve social life is an active hope; others should be at ease with their 'waiting for hope'. Not having the right to hope means taking for granted that only a very few can expect changes. The most we can do is ask those with active hope what they are going to do with it: What does it mean to hope from the privilege of having faith? Or hoping from a high social position? Or from a specific kind of work granting a future? Fromm thought that hope in the new order is active hope, but it is also exclusive hope.

Hope, especially active hope, is not just a feeling. It is not about knowing that we can change reality or even having the sense of our own capacity for doing it. Optimism is not hope, but just a positive outlook of reality. Pessimism is not lack of hope, but mostly a denial of our and others' talents when aiming to make a difference in society. Actually pessimism and optimism find their root in the conviction that nothing can be done, both lay on laziness. Pessimists do not do anything as they think nothing can actually be done. Optimists do not do anything under the observation that things are as good as it gets (O'Callaghan 2011, 5). Both are passive and both refer to passive hope and bear waiting hopes. To define active hope as an intention above every personal feeling, we need to consider the uniqueness of our being humans in the world. As no one would reasonably think that he or she can effectively change society alone, active hope creates interest for others, leads us to provoke relational interchanges, multiplying our capacity of understanding others, and grows common empathy in society.

Active hope demands from us in the measure of its goal, so it is essential to distinguish among hopes and the Hope. The latter being the ultimate ground for our own life. "The capacity to suffer for the sake of the truth is the measure of humanity. Yet this capacity to suffer depends on the type and extent of the hope that we bear within us and build upon"(Benedict XVI 2007). Hope, when it is real, requires a goal exceeding individual capacities. In this sense it is always transcendent to us, and active hope never stops in the individual, it goes beyond us. It can thus be defined as intergenerational, cross-cultural and global.

Startup hubs could foster reflection and putting different worlds together, if they will flourish new apps or using digital tools its fine, the important thing is that they create awareness and personal changes. Their goal is not programming but 
rather assuring us that something can be done for shaping society according to integral human development. For that, they do not specify what to do, rather stressing that something can actually be done for including people in the social and economic system, for overcoming 'a throwaway culture', being in close contact with those who suffer the most (Francis 2013, 53). It is in this specific role that startup hubs become relevant for faith-based institutions and so also for the Catholic Church. Startup hubs neither aim to foster the specific use of tools nor of communication and management techniques. And they are not in place for leveraging the minority condition of groups stressing doctrinal or liturgical orientations either. Startup initiatives for faith-based organizations include contents able to encourage change of personal behavior towards becoming its best.

\section{References}

Atkinson, A. (2015). Inequality: What Can Be Done? Cambridge MA: Harvard University Press.

Basic, G. (2013). A case of what? Methodological lessons from a reanalysis of conflicts within Swedish Juvenile Care. Journal of Comparative Social Work, 8, 1-29.

Benedict XVI. (2007). Spe Salvi: On Christian Hope. Vatican City: LEV Press. available online: www.vatican.va

Benedict XVI. (2009). Caritas in Veritate: On Integral Human Development in Charity and Truth. Vatican City: LEV Press. available online: www.vatican.va

Carr, N. (2010). The Shallows: What the Internet is Doing to Our Brains. New York: W. W. Norton \& Co.

Carty, V. (2015). Social Movements and New Technology. New York: Westview Press.

Flannery, K. (2013). Action and Character According to Aristotle: The Logic of the Moral Life. Washington: CUA Press.

Francis. (2013). Evangelii Gaudium: On the Proclamation of the Gospel in Today's World. Vatican City: LEV Press. available online: www.vatican.va

Francis. (2015). Laudato Si: On Care of Our Common Home. Vatican City: LEV Press. available online: www.vatican.va

Fromm E. (1968). The Revolution of Hope: Towards a Humanized Technology. New York: Harper \& Row.

Habermas, J. (1990). On the Logic of the Social Sciences. Cambridge MA: MIT Press.

Hayek, F. (1976). Law, Legislation and Liberty: A New Statement of the Liberal Principles of Justice and Political Economy. London: Routledge.

Herrera, F. (2016). El Renacer del Relato Social como oportunidad para la revitalización de la comunicación narrativa de la Iglesia. MTS diss., Pontifical University of the Holy Cross.

Hood, C. (2006). Transparency in Historical Perspective, in Transparency: The Key to Better Governance? Proceedings of the British Academy, edited by Christopher Hood and David Heald, 3-23. New York: Oxford University Press.

Howard, P. (2015). Pax Technica: How the Internet of Things May Set Us Free or Lock Us Up. Yale: Yale University Press.

Jaeger, W. (1957). Paideia. Madrid: Fondo de Cultura Económica.

John Paul II. (1991). Centesimus Annus: On the Hundreth Anniversary of Rerum Novarum. Vatican City: LEV Press. available online: www.vatican.va

Laudicina, P. (2012). Beating the Global Odds: Successful Decision-making in a Confused and Troubled World. New Jersey: Wiley.

Llano, A. (2016). Otro Modo de Pensar. Pamplona: EUNSA.

Luhmann, N. (1997). The Control of Intransparency. System Research Behavior, 15, 359-371.

Mazzucato, M. (2011). The Entrepreneurial State. London: Demos.

Monod, J. (1972). Chance and Necessity: An Essay on the Natural Necessity of Modern Biology. New York: Vintage Books.

Moyo, D. (2012). Winner Take All: China's Race for Resources and What It Means for the World. New York: Basic Books.

O'Callaghan, P. (2011). Christ Our Hope: An Introduction to Eschatology. Washington: Catholic University of America Press.

Pannenberg, W. (1986). Ética y Eclesiología. Salamanca: Sígueme. 
Rabari, C., \& Storper, M. (2013). The Digital Skin of Cities: Urban Theory and Research in the Age of the Sensored and Metered City. PhD diss., University of California Los Angeles.

Ragin, C., \& Becker, H. S. (1992). What is a Case? Exploring the Foundations of Social Inquiry. Cambridge: Cambridge University Press.

Rodríguez-Luño, A. (2016). Economia e Libertà, in La libertà in discussione. Tra cambiamenti culturali e progresso scientifico, 61-70. Roma: Edusc.

Romera, L. (2016). Itinerarios de Metafísica. Roma: Edusc.

Schumacher, E. F. (1973). Small Is Beautiful: A Study of Economics As If People Mattered. New York: Harper Collins.

Scruton, R. (2009). Beauty: A Very Short Introduction. Oxford: Oxford University Press.

Taylor, C. (1991). The Malaise of Modernity. Toronto ON: Anansi Press.

Taylor, C. (2007). Secular Age. Cambridge MA: Harvard University Press.

United Nations. (2016)2016. "2030 Global Agenda for Sustainable Development”. New York: United Nations.

WEF. (2014). "Insight Report Enhancing Europe's Competitiveness: Fostering Innovation-driven Entrepreneurship in Europe". Geneva: World Economic Forum.

WEF. (2015). "Global Agenda Towards towards A New Global Consciousness". Geneva: World Economic Forum.

\section{Copyrights}

Copyright for this article is retained by the author(s), with first publication rights granted to the journal.

This is an open-access article distributed under the terms and conditions of the Creative Commons Attribution license which permits unrestricted use, distribution, and reproduction in any medium, provided the original work is properly cited. 